\title{
Continuing Medical Education
}

\section{The TURP syndrome valerie enesen nas w w frecece}

This article discusses the presentation, aetiology, treatment and prevention of central nervous system disturbances after transurethral resection of the prostate. Nausea and vomiting, visual symptoms, and altered states of consciousness have been reported as complications due to intravascular absorption of irrigating fluid. Hypotonicity after absorption of the irrigating fluid causes cerebral oedema. Hyperglycinaemia may cause visual disturbances and hyperammonaemia may cause delayed coma.

Cet article discuse de la présentation, l'aetiologie, le traitement et la prévention des problèmes du système nerveux central après RTUP. Les nausées, les vomissements, less symptômes visuels, l'altération de la conscience ont été rapportés comme complications dû à une absorption intra-vasculaire du liquide d'irrigation. L'hypotonicité après absorption du liquide d'irrigation provoque l'adème cérébral. L'hyperglycinémie peut causer des perturbations de la vision et l' hyperammoniémie peut provoquer un coma retardé.

\section{Key words}

COMPLICATIONS: TURP syndrome;

SURGERY: urological;

IONS: sodium.

Department of Anaesthesia, WMC 3B2.32, University of Alberta Hospitals, $8440-112$ Street, Edmonton, Alberta T6G $2 \mathrm{~B} 7$.

Address correspondence to: Dr. V. Jensen.

Accepted for publication 27th June, 1990.

\section{Contents}

Presentation

- Altered states of consciousness

- Visual disturbances

Aetiology

- Irrigating fluid

- properties

- absorption

- Effects of absorption

- sodium

- osmolality

- tonicity

- colloid osmotic pressure

- potassium

- Glycine

- high concentrations of glycine

- metabolism

- ammonia

Treatment

- The mildly symptomatic patient

- The unconscious patient

- Hypertonic saline

- Neurological complications

Prevention

References

Self-assessment questions

Central nervous system (CNS) complications after intravascular absorption of irrigating fluid during transurethral resection of the prostate (TURP) range in severity from minor to life-threatening and depend on the rate and amount of absorption. Glycine, 1.5 per cent, is the most commonly used irrigating fluid. Because glycine is a permeant solute, intracellular oedema may occur upon absorption. Toxic effects may occur from high concentrations of ammonia, which is a by-product of the metabolism of glycine, and from high concentrations of glycine itself. Acute severe hypotonicity leading to cerebral oedema is the most serious complication and requires therapy with hypertonic saline. The rate at which the hyponatraemia should be corrected is controversial. Hyperglycinaemia may cause visual disturbances and 
TABLE I TURP syndrome - presentation

\begin{tabular}{ll}
\hline CVS Components & CNS Components \\
\hline Increase in central venous & Apprehension \\
pressure & Disoricntation \\
Bradycardia & Nausea \\
Hypertension & Visual disturbances \\
Angina & Stupor \\
Electrocardiographic changes & Coma \\
CV collapse & Scizures \\
\hline
\end{tabular}

hyperammonaemia may cause delayed coma but both require only supportive therapy. Nausea and vomiting may be side-effects of hyponatraemia or may result from elevated concentrations of nonessential amino acids which are metabolites of glycine. The TURP syndrome is an iatrogenic surgical complication but the responsibility for its diagnosis and treatment often falls upon the anaesthetist.

Transurethral resection of the prostate is frequently complicated by absorption of the irrigating fluid which is used to distend the bladder during surgery. ${ }^{1-3}$ Because of this absorption, there are continuous and complicated shifts of water and electrolytes in the body. ${ }^{4}$

\section{Presentation}

The TURP syndrome comprises CNS and cardiovascular system (CVS) alterations (Table I) resulting from intravascular absorption of irrigating fluid. ${ }^{1,5}$

Nausea and vomiting, visual disturbances, and altered states of consciousness have been reported to occur after TURP.' The aetiology of these CNS disturbances has been attributed to hyponatraemia, hyperglycinaemia, and/or hyperammonaemia. Hyponatraemia may occur when any of the irrigating fluids is used, but hyperglycinaemia and hyperammonaemia may occur only when glycine is used as the irrigating fluid. This review will consider the presentation, aetiology, treatment, and prevention of these CNS disturbances.

\section{Altered states of consciousness}

Acutely altered states of consciousness from mild confusion to stupor and coma have been reported after TURP. ${ }^{1,2,6}$ Hoekstra noted that one of 30 patients had an altered sensorium after TURP using glycine 1.5 per cent as the irrigating fluid. ${ }^{7}$ Henderson reviewed the charts of 2000 patients who had undergone TURP with glycine 1.5 per cent and identified 78 cases of hyponatraemia. Of these, an unidentified number had agitation or vomiting or confusion, and 14 deteriorated into a comatose or semicomatose state. $^{6}$

The onset of the comatose state is quite variable, ranging from $15 \mathrm{~min}$ after surgery has started to ten hours after surgery has been completed. The neurological examination is consistent with a metabolic encephalopathy. In the more severe cases the patient may have focal or generalized seizures. Mild papilloedema and decerebrate movements may be present. The coma lasts from 8 to 120 hr. Upon discharge from hospital, the 14 cases of coma after TURP reported by Henderson were neurologically unchanged from the premorbid state.

\section{Visual disturbances}

Visual disturbances have been reported as a complication of TURP but only when glycine has been used as the irrigating fluid and when hyponatraemia has occurred. ${ }^{8}$ The reports range from "dimming of vision", "light perception only," to "no light perception" for several hours. ${ }^{9}$ Patients are usually alert when altered vision is present but they also complain of nausea. The onset of symptoms may occur from $30 \mathrm{~min}$ after the start of resection to six hours following its completion. Vision returns to normal within 2 to $12 \mathrm{hr}$. Fundoscopic examination is normal with no papilloedema and the pupillary response to light is maintained in those patients who are minimally affected. However, patients whose visual acuity is decreased to light often only have dilated and unresponsive pupils. The intraocular pressure remains normal. ${ }^{10}$ Electroretinograms are abnormal in patients with visual impairment, ${ }^{9,11}$ while visual evoked potentials are not consistently affected. "'

\section{Aetiology}

\section{Irrigating fluid}

\section{PROPERTIES}

The properties of the ideal irrigating fluid are shown (Table II) because intravascular absorption of the irrigating fluid is the cause of the TURP syndrome. ${ }^{12}$ The fluid must be nonelectrolytic to disperse the electrical current. Water allows clear visibility by the surgeon but it is hypotonic and causes haemolysis when absorbed. ${ }^{2}$ Glycine, sorbitol, mannitol, and urea are solutes which have been added to water to bring its osmolality closer to that of

TABLE II The ideal irrigating fluid
Isotonic
Nonhacmolytic
Non-toxic when absorbed
Nonelectrolytic
Not metabolized
Allows clear visibility
Does not influence osmolality
Rapidly excreted
Osmotic diuretic 
TABLE III Factors influencing absorption of irrigating fluid

Hydrostatic pressure of irrigation fluid

Number and size of venous sinuses opened

Peripheral venous pressure

Duration of surgery

Experience of surgeon

plasma. Ideally these solutes and their metabolites should be nontoxic. Mannitol is not metabolized but undergoes urinary elimination; sorbitol is metabolized to glucose; and glycine and its metabolites may not be as nontoxic as was initially thought.

\section{ABSORPTION}

During TURP both intravascular and extravascular absorption of irrigating fluid may occur. Intravascular absorption occurs through open prostatic vessels when the irrigating pressure exceeds venous pressure. Perivesical absorption occurs with perforations of the prostatic capsule. A radioisotope technique found that only 29 per cent of the absorbed fluid was absorbed intravascularly. ${ }^{13}$ Factors which influence the extent of absorption are listed in Table III. $^{3}$ Irrigating fluid absorption may occur throughout the TURP although the risk appears to be greatest $30 \mathrm{~min}$ after surgery commences. ${ }^{14}$ Increased blood loss during TURP coincides with intravascular but not extravascular absorption. ${ }^{14}$

\section{Effects of absorption}

\section{SODIUM}

The absorption of large amounts of electrolyte-free irrigating fluid intravascularly leads to dilutional hyponatraemia. ' With extravascular absorption, hyponatraemia is less pronounced and could be delayed to the morning after the TURP. ${ }^{15} \mathrm{~A}$ decrease in serum sodium concentration to less than $120 \mathrm{mmol} \cdot \mathrm{L}^{-1}$ indicates a severe TURP reaction. ${ }^{1.2}$ A decrease in serum $(\mathrm{Na})$ of 20 to $30 \mathrm{mmol}$. $\mathrm{L}^{-1}$ implies absorption of 3 to $4 \mathrm{~L}^{4}$ Hahn concluded that continuous and complicated shifts of water and electrolytes occur in the body during TURP. ${ }^{4}$ The changes in serum $(\mathrm{Na})$ were related to glycine absorption during the course of TURP. The serum (Na) at the end of TURP only roughly correlated with the volume of irrigating fluid which was intravascularly absorbed. The absorption time is also an important factor; only rapid massive absorption can produce the very low sodium concentrations typical of severe TURP reactions. Diffusion of water into the intracellular space and renal elimination of excess water are factors which reduce the degree of hyponatraemia. ${ }^{4}$

Certain signs and symptoms have been observed as
TABLE IV Symptoms and acute changes in Serum (Na)

\begin{tabular}{lll}
\hline Serum $(\mathrm{Na})$ & Electrocardiogram & CNS \\
\hline $120 \mathrm{mmol} \cdot \mathrm{L}^{-1}$ & Possibly widening QRS & $\begin{array}{l}\text { Restlessness } \\
\text { Confusion }\end{array}$ \\
$115 \mathrm{mmol} \cdot \mathrm{L}^{-1}$ & Widened QRS & Nausea \\
& Elevated ST segment & Sernicoma \\
$100 \mathrm{mmol} \cdot \mathrm{L}^{-1}$ & Ventricular tachycardia & Seizures \\
& or fibrillation & Coma \\
\hline
\end{tabular}

serum Na concentrations decrease (Table IV). ${ }^{1.16}$ Symptoms of hyponatraemia are related to the speed of its development. Acute changes produce more symptoms than chronic hyponatraemia. ${ }^{17}$ After 24 to $48 \mathrm{hr}$ of sustained hypotonicity, the brain cells adapt by extruding solute, which reduces cell swelling. ${ }^{18}$

\section{OSMOLALITY}

Osmolality is an expression of the total number of particles in a given weight of solvent. Osmolality refers to the number of osmoles per kilogram of solvent and osmolarity refers to the number of osmoles per litre of solution. At the solute concentrations of the body fluids, the two measurements correspond so closely that no correction is required. ${ }^{19}$ Glucose, urea and sodium and its accompanying anions contribute almost 100 per cent of the measured osmolality of plasma under normal circumstances. The formula used to calculate plasma osmolality is $2 \times(\mathrm{Na})+$ (glucose) + (urea) where the concentrations of these compounds are measured in mmol $\cdot \mathrm{L}^{-1}$. The actual measurement of osmolality is based on freezing point depression and the difference between measured and calculated osmolality is called the osmolal gap. ${ }^{19}$

Glycine, 1.5 per cent, has an osmolality of 188 mosm $\cdot \mathrm{kg}^{-1}$ which is lower than the normal plasma osmolality of 285 mosm $\cdot \mathrm{kg}^{-1} \cdot{ }^{20}$ When this solution is absorbed intravascularly, hyponatraemia may occur but the serum osmolality may remain close to normal. Desmond studied 72 patients undergoing TURP with glycine 1.2 per cent. ${ }^{21}$ Nineteen of these 72 patients developed decreases in serum ( $\mathrm{Na}$ ) but only two patients had decreases in serum osmolality. In a patient with TURP syndrome, the osmolality gap will be greater than $10 \operatorname{mosm} \cdot \mathrm{kg}^{-1}$, which indicates the presence of solute other than that included in the calculated osmolality. ${ }^{19}$

\section{TONICITY}

Tonicity describes the osmotically effective solute in a solution. Effective solutes are relatively restricted to one particular body fluid compartment and are able to exert an osmotic force for water movement from other compartments. Tonicity cannot be measured but can be estimated as follows: $2 \times$ (sodium) + (glucose).$^{22}$ Mannitol and 
sorbitol are osmotically effective solutes and would be included in this calculation if they were absorbed intravascularly. Urea passes freely across all membranes and is not an effective solute. ${ }^{19}$ Glycine is a small amino acid which moves intracellularly upon absorption. ${ }^{12}$

In summary, sorbitol and mannitol contribute to tonicity and will increase the extracellular fluid volume when absorbed. However, urea and glycine do not contribute to tonicity and will therefore expand both the intracellular and extracellular spaces. The changes in body fluid tonicity, rather than changes in osmolality, lead to alterations in cell volume. Acute hypotonicity is associated with cerebral oedema. ${ }^{22}$ The signs of metabolic encephalopathy associated with the TURP syndrome have been attributed to cerebral oedema ${ }^{13}$ but other authors have also implicated the toxicity of glycine and its break-down products. '

\section{COLLOID OSMOTIC PRESSURE}

With an irrigant absorption of between 0.5 and $2.8 \mathrm{~L}$, plasma protein concentrations decrease to 70 to 80 per cent of preoperative levels. ${ }^{23}$ However, this effect alone does not promote cerebral oedema. An acute decrease in oncotic pressure does not promote an increase in cerebral water content in the noninjured brain. ${ }^{24}$

\section{POTASSIUM}

There is no change in serum (K) during TURP. However, there may be a small increase of $0.5 \mathrm{mmol} \cdot \mathrm{L}^{-1}$ in those patients experiencing intravascular absorption of glycine. ${ }^{15}$ The cause is not known, but it has been speculated that high concentrations of glycine may interfere with transmembrane electrolyte exchange. ${ }^{12}$ Some haemolysis has been reported with the use of glycine, 1.5 per cent, ${ }^{20}$ and this may contribute to the increase in serum (K).

\section{Glycine}

\section{HIGH CONCENTRATIONS OF GLYCINE}

There may be a higher incidence of CNS disturbances with glycine than with other irrigating solutions. Two groups of patients undergoing TURP were compared when glycine 1.5 per cent and sorbitol three per cent were used. ${ }^{25}$ Three of the 21 patients in the glycine group exhibited signs of encephalopathy but the 12 patients in the sorbitol group did not.

The 1.5 per cent solution of glycine contains 1000 times the normal concentration of glycine in plasma. ${ }^{26}$ The serum glycine concentration after TURP was elevated to ten times normal levels in one study even though sodium concentrations remained normal. ${ }^{27}$ Two of 21 patients in this series had some nausea associated with the elevated glycine concentrations but the others showed no adverse effects. Visual impairment may occur when

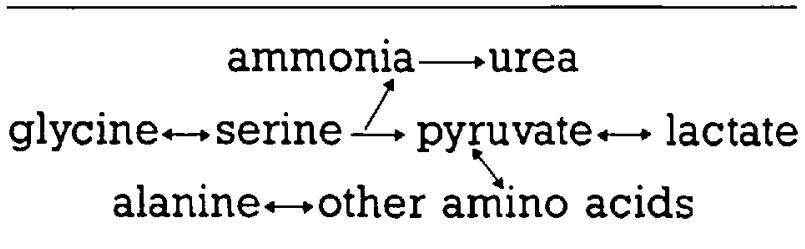

FIGURE Mctabolism of glycine. (Modified from Hahn. ${ }^{29}$ )

serum glycine concentrations are 30 times normal (at $\left.4000 \mu \mathrm{mol} \cdot \mathrm{L}^{-1}\right) .{ }^{11}$ Glycine is an inhibitory neurotransmitter in the mammalian central nervous system ${ }^{28}$ and may act on receptors in the retina to cause blindness. The mechanism of visual loss may be a function both of CNS toxicity from glycine and hypotonicity resulting in cerebral oedema. ${ }^{8}$

\section{METABOLISM}

Glycine is a simple amino acid which is involved with numerous reactions in the metabolic chain. The Figure shows a simplified version of the metabolism of glycine. Ammonia is a by-product of this reaction and other nonessential amino acids are metabolites. The symptoms of nausea and vomiting have been associated with a rapid increase in the concentrations of several amino acids, including serine, alanine, and glutamate. ${ }^{29}$ Urinary excretion is not important for elimination of glycine from the body. ${ }^{12}$

\section{AMMONIA}

High ammonia concentrations have been implicated in the pathogenesis of coma after TURP. The cerebral depression due to hyperammonaemia may enhance or act independently of dilutional hyponatraemia. Deterioration in cerebral function has been documented when blood ammonia concentration exceeds $150 \mu \mathrm{mol} \cdot \mathrm{L}^{-1} .^{30}$ Hyperammonaemia causes an excess of cerebral inhibitory neurotransmitters and a deficit of excitatory neurotransmitters which lead to coma.

A marked elevation of glycine concentration may be associated with normal ammonia concentrations. ${ }^{7}$ Conversely, some patients with high ammonia levels after TURP have only mild glycine elevations, possibly reflecting a more rapid breakdown of absorbed glycine. ${ }^{7}$ Ammonia is normally converted to urea in the liver through the urea cycle. Patients with a nutritional deficiency of arginine ${ }^{3}$ and those with pre-existing liver disease $^{31}$ are more likely to develop high ammonia concentrations.

\section{Treatment}

The mildly symptomatic patient If a patient exhibits nausea, vomiting, agitation, confu- 
TABLE V Principles of management of comatose patients

\author{
1 Assure oxygenation \\ 2 Maintain circulation \\ 3 Lower intracranial pressure \\ 4 Stop scizures \\ 5 Treal infection \\ 6 Restore acid-base balance and electrolyte balance \\ 7 Adjust body temperature
}

sion and/or visual disturbances, while the CVS is stable, then monitoring and observation should continue until the symptoms resolve. Blood should be sent for electrolyte estimation. A serum sodium concentration of 120 $\mathrm{mmol} \cdot \mathrm{L}^{-1}$ is the borderline between mild and severe reactions.' A loop diuretic may be given if there is evidence of fluid overload, but most patients in this category will diurese spontaneously and may require no further treatment. ${ }^{1,2}$

If there are visual disturbances, an ophthalmologist should be consulted to eliminate other causes of impaired vision. There is no specific treatment for the visual disturbances of the TURP syndrome. The patient should be reassured that vision will return by the next day. ${ }^{8}$

\section{The unconscious patient}

The approach to the unconscious patient is well outlined in the monograph by Plum and Posner. ${ }^{32}$ Certain general principles of management should be addressed (Table V). The differential diagnosis of states causing sustained unresponsiveness is described in Table VI. If the patient has metabolic encephalopathy, the anaesthetist must rule out other potentially treatable conditions such as diabetic coma, hypoxia, or drug interactions before the TURP syndrome is diagnosed. The immediate tests to evaluate metabolic coma are listed in Table VII, and in the case of the TURP patient, may include serum glycine and ammonia concentrations.

The presence of an acute hypotonic state is lifethreatening if the serum ( $\mathrm{Na}$ ) is less than $120 \mathrm{mmol} \cdot \mathrm{L}^{-1}$ and the patient is severely symptomatic. ${ }^{22}$ The therapy of symptomatic hypotonicity is directed at increasing extracellular fluid tonicity in order to shift water from the intracellular to the extracellular fluid, thereby ameliorating cerebral oedema. ${ }^{1,22}$. This may be accomplished with the use of hypertonic saline in the patient with normal renal function ${ }^{1,6.20 .33}$ or with the use of haemodialysis if the patient has chronic renal failure. ${ }^{34}$ There is no specific treatment for hyperglycinaemia or hyperammonaemia but the concentrations of these substances have been reported to return to normal by the next day. ${ }^{25.27}$

Additional drugs in the treatment of the TURP syndrome have been suggested. Sodium bicarbonate, 8.4 per cent, may be used if hypertonic saline is not available. ${ }^{35}$
TABLE VI Differential diagnosis of sustained unresponsiveness

1 Supratentorial mass lesions compressing or displacing the
diencephalon or brainstem
2 Subtentorial masses or destruction
3 Metabolic coma
4 Psychiatric unresponsiveness

Administration of calcium may be beneficial in the presence of an acute reduction in serum calcium concentration. $^{35}$

\section{Hypertonic saline}

Even though there is agreement that acute symptomatic hypotonicity should be treated, the details of therapy are controversial. Henderson recommended the administration of $100 \mathrm{ml}$, five per cent saline over one to two hours, repeating the measurement of serum sodium concentration and then giving another $100 \mathrm{ml}$ if necessary. ${ }^{6}$ Beal suggested the use of 100 to $200 \mathrm{ml}$ of three per cent hypertonic saline but the rate of administration was not reported. ${ }^{20}$ Some authors recommend the simultaneous administration of furosemide and hypertonic saline to reduce fluid overload. ${ }^{1.20,33}$ Hypertonic saline is only infused until the serum $(\mathrm{Na})$ has been increased to 120 $\mathrm{mmol} \cdot \mathrm{L}^{-1}$. Complete correction of the hypotonicity is then achieved gradually by fluid restriction over the next few days. ${ }^{22}$ An alternative approach is to calculate the sodium requirements based on total body water and then to administer this amount as hypertonic salinc. ${ }^{22}$ However, there is such great variability in response that undercorrection or overcorrection may occur. ${ }^{36}$

Concern has been expressed that the administration of hypertonic saline in the treatment of the TURP syndrome may cause hyperosmolality. ${ }^{34}$ However, there is little evidence that hyperosmolality per se is harmful, and the major concern depends on whether its development has been accompanied by major fluid shifts. ${ }^{37}$ If the patient is

TABLE VII Evaluation of metabolic coma

A Venous Blood
1 Glucose
2 Electrolytes $\left(\mathrm{Na}^{+}, \mathrm{K}^{+}, \mathrm{Cl}^{-}, \mathrm{CO}_{2}, \mathrm{Ca}^{++}, \mathrm{PO}_{4}^{-}\right)$
3 Urea or creatinine
4 Osmolality
5 Glycine
6 Ammonia
B Arterial blood
I $\mathrm{HCO}_{3}^{-}$
2 pH
$3 \mathrm{PO}_{2}$
$4 \mathrm{PCO}_{2}$
C Electrocardiogram


symptomatic from hypotonicity, the appropriate therapy is to normalize the tonicity, even though osmolality would further increase. ${ }^{22}$

\section{Neurological complications}

Neurological complications have been reported after very rapid correction of hyponatraemia, but there is still a lack of agreement regarding the safe rate of correction. If hyponatraemia is corrected too quickly, the rapid intracellular volume contraction could lead to the abrupt decrease of cerebral volume and, consequently, to intracranial haemorrhage. ${ }^{22}$ Another concern is that cerebral demyelinating lesions have been associated with excessively rapid correction of chronic hyponatraemia ${ }^{38} \mathrm{Grad}$ ual neurological deterioration has developed one to several days after complete or partial correction of chronic hyponatraemia, leading to pseudobulbar palsy and quadriparesis. However, the pathophysiology of chronic hyponatraemia is different from that of acute hyponatraemia. Demyelinating lesions have not yet been reported after correction of acute hyponatraemia in the TURP patient. A recent animal study showed that rapid correction of hyponatraemia, without overcorrection, can cause neurological disease. ${ }^{36}$ The same study concluded that myelinolysis was greater in the group with protracted hyponatraemia than the group with hyponatraemia of short duration. ${ }^{36}$

\section{Prevention}

The CNS complications after TURP are preventable with the efforts of both the surgeon and the anaesthetist. The resection time should be limited to one hour. ${ }^{2}$ The hydrostatic pressure of the irrigating fluid should not exceed $6.9 \mathrm{kPa}\left(70 \mathrm{~cm} \mathrm{H}_{2} \mathrm{O}\right){ }^{1}$ The early detection of cerebral symptoms is more feasible if a spinal anaesthetic is administered than if general anaesthesia is used. ${ }^{1}$ The anaesthetist should institute the same monitoring regime with the spinal anaesthetic as would be used with a general anaesthetic. Rapid measurement of serum $(\mathrm{Na})$ should be available within the institution. Hypotonic intravenous fluids should not be administered. Hypotension from the spinal anaesthetic is better treated with vasopressors rather than with large boluses of intravenous crystalloid. Lastly, open prostatectomy should be considered a valid alternative to transurethral prostatectomy. The evidence indicates increased rates of reoperation and reduced five-year survival after transurethral prostatectomy. ${ }^{39}$

\section{Acknowledgements}

The author wishes to thank Dr. Brendan Finucane for reviewing the manuscript and Ms. Cindy Crandall for secretarial assistance.

\section{References}

1 Hatch $P D$. Surgical and anaesthetic considerations in transurethral resection of the prostate. Anacsth Intensive Care 1987; 15: 203-11.

2 Marx GP, Orkin LR. Complications associated with transurethral surgery. Anesthesiology 1962; 23: 80213.

3 Desmond J. Complications of transurethral prostatic surgery. Can Anaesth Soc J 1970; 17: 25-36.

$4 \mathrm{Hahn}$ RG. Relations between irrigant absorption rate and hyponatremia during transurethral resection of the prostate. Acta Anaesthesiol Scand 1988; 32: 53-60.

5 Sunderrajan S, Bauer JH, Vopat RL, Wanner-Barjenbrush $P$, Hayes $A$. Post transurethral prostatic resection hyponatremic syndrome: case report and revicw of the literature. Am J Kid Dis 1984; 4: 80-4.

6 Henderson DJ, Middleton RG. Coma from hyponatremia following transurethral resection of the prostate. Urology 1980; 15: 267-71.

7 Hoekstra PT, Kahnoski R, McCamish MA, Bergen W, Heetderks $D R$. Transurethral prostatic resection syndrome - a new perspective: encephalopathy with associated hyperammonemia. J Urology 1983; 130: 704-7.

8 Kay MC, Kay J, Begun F, Yeung JE. Vision loss following transurethral resection of the prostate. J Clin Neuro Ophthalmol 1985; 5: 273-6.

9 Creel DJ, Wang $J M$, Wong KC. Transicnt blindness associated with transurethral resection of the prostate. Arch Ophthalmol 1987; 105: 1537-9.

10 Peters $K R$, Muir $J$, Wingard $D W$. Intraocular pressurc after transurethral prostatic surgery. Anesthesiology 1981; 55: 327-9.

11 Wang JM, Creel DJ, Wong KC. Transurethral resection of the prostate, serum glycine levels, and ocular cvoked potentials. Anesthesiology 1989; 70: 36-41.

12 Norlen $H$, Allgen L, Vinnars E, Bedrelidou-Classon $G$. Glycine solution as an irrigating agent during transurethral prostatic resection. Scand J Urol Nephrol 1986; 20: 19-26.

13 Oester A, Madson PO. Determination of absorption of irrigating fluid during transurethral resection of the prostate by means of radioisotopes. J Urology 1969; 102 : $714-9$.

14 Hahn R, Berlin T, Lewenhaupt A. Irrigating fluid absorption and blood loss during transurethral resection of the prostate studied with a regular interval monitoring method. Scand J Urol Nephrol 1988; 22: 23-30.

15 Hahn R, Berlin T, Lewenhaupt A. Factors influencing the osmolality and the concentrations of blood haemoglobin and electrolytes during transurcthral rescction of the prostate. Acta Anaesthesiol Scand 1987; 31:601-7.

16 Aasheim $G M$. Hyponatremia during transurethral surgery. Can Anaesth Soc J 1973; 20: 274-80. 
17 Arieff AI, Llach F, Massry SG. Neurological manifestations and morbidity of hyponatremia: corrclation with brain water and electrolytes. Medicine 1976; 55: 121-9.

18 Narins $R G$. Therapy of hyponatremia: docs haste make waste? N Engl J Med 1986; 314: 1573-5.

19 Gennari FJ. Serum osmolality: uses and limitations. N Engl J Med 1984; 310: 102-5.

20 Beal JL, Freysz $M$, Bershelon $G, D^{\prime}$ Athis $P$, Briet $S$, Wilkening $M$. Consequences of fluid absorption during transurethral resection of the prostate using distilled water or glycine 1.5 per cent. Can J Anaesth 1989; 36: 278-82.

21 Desmond J. Serum osmolality and plasma clectrolytes in patients who develop dilutional hyponatremia during transurethral surgery. Can J Surg 1970; 13: 116-21.

22 Alvis $R$, Geheb $M, \operatorname{Cox} M$. Hypo- and hyper-osmolar states: diagnostic approaches. In: Arieff Al, De Fronza RA (Eds.). Fluid, Electrolyte and Acid-base Disorders. New York: Churchill Livingstone Inc, 1985: 185-219.

23 Hahn RG. Dilution of blood proteins due to irrigant absorption in transurethral prostatic resection. Scand $J$ Urol Nephrol 1989; 23: 97-102.

24 Zornow MH, Todd M, Moore $S$. The acute cerebral effects of changes in plasma osmolality and oncotic pressurc. Anesthesiology 1987; 67: 936-41.

25 Shephard RL, Kraus RE, Babayan RK, Siroky MB. The role of ammonia toxicity in the post transurethral prostatectomy syndrome. Br J Urol 1987; 60: 349-5I.

26 Zucker JR, Bull AP. Independent plasma levels of sodium and glycine during transurethral resection of the prostate. Can Anaesth Soc J 1984; 31: 307-13.

27 Gecelter LG, Gascoigne H. Safety and efficacy of a 1.5 per cent glycine solution as an irrigation medium in prostatic surgery. S Afr Med J 1984; 65: 693-4.

28 Pycock $L$, Kerwin $R W$. The status of glycine as a supraspinal neurotransmitter. Life Sci 1981;28: 2679_ 86.

29 Hahn $R G$. Serum amino acid patterns and toxicity symptoms following the absorption of irrigant containing glycine in transurethral prostatic surgery. Acta Anacsthesiol Scand 1988; 32: 493-501.

30 Roesch RP, Stoelting RK, Lingeman JE, Kahnoski RJ, Backes $D J$, Gephardt $S A$. Ammonia toxicity resulting from glycine absorption during a transurethral resection of the prostatc. Anesthesiology 1983; 58: 577-9.

31 Frink E, DiGiovanni D, Davis J, Brown B. Serum ammonia levels in response to glycine infusion in normal and cirrhotic rats. Anesth Analg 1989; 69: 776-82.

32 Plum F, Posner JB. The Diagnosis of Stupor and Coma. 3rd ed. Philadelphia: FA Davis Company, 1980; 349-68
33 Ayus JC, Olivero JJ, Frommer JP. Rapid correction of severe hyponatremia with intravenous hypertonic saline solution. Am J Med 1982; 72: 43-8.

34 Campbell $H$, Fincher $M$, Sklar $A$. Severe hyponatremia without severe hypo osmolality following transurethral resection of the prostate in end-stage renal disease. Am J Kid Dis 1988; 12: 152-5.

35 Butt $D$, Wright I, Elk $R$. Hypoosmolar intravascular volume overload during anaesthesia for transurethral prostatectomy. S Afr Med J 1985; 67: 1059-61.

36 Illowsky $B P$, Laureno $R$. Encephalopathy and myelinolysis after rapid correction of hyponatremia. Brain 1987; 110: 855-67.

37 Loeb J. The hyperosmolar state. N Engl J Med 1974; 290; 1184-7.

38 Sterns RH, Rigg.J JE, Schochet SS. Osmotic demyelination syndrome following correction of hyponatremia. $\mathrm{N}$ Engl J Med 1986; 314: 1535-42.

39 Roos NP, Wennberg JE, Malenka DJ et al. Mortality and reoperation after open and transurethral resection of the prostate for benign prostatic hyperplasia. N Engl J Med 1989; 320: 1120-4. 


\section{Self-Assessment Questions}

A. SELECT THE SINGLE CORRECT ANSWER

1 Which of the following is not a metabolite of glycine?
A mannitol
B ammonia
C serine
D pyruvate

2 The serum $(\mathrm{Na})$ which is the borderline between mild and severe TURP reactions is:
A $130 \mathrm{mmmol} \cdot \mathrm{L}^{-1}$
B $\quad 120 \mathrm{mmmol} \cdot \mathrm{L}^{-1}$
C $115 \mathrm{mmmol} \cdot \mathrm{L}^{-1}$
D $110 \mathrm{mmmol} \cdot \mathrm{L}^{-1}$

3 When a patient develops the TURP syndrome, the osmolal gap is:
A increased more than $10 \operatorname{mosm} \cdot \mathrm{kg}^{-1}$
B unchanged
C decreased
D increased less than $10 \mathrm{mosm} \cdot \mathrm{kg}^{-1}$

4 Visual impairment after TURP is associated with glycine concentrations which are:
A normal
B decreased
C increased ten times normal
D increased thirty times normal

5 The ideal irrigating fluid has the following properties except:
A nonelectrolytic
B allows clear visibility
C rapidly excreted
D haemolytic

B. FOR EACH QUESTION, ONE OR MORE OF THE COMPLETIONS IS CORRECTLY ANSWERED AS FOLLOWS:
A If only 1,2 and 3 are correct
B If only 1 and 3 are correct
C If only 2 and 4 are correct
D If all are correct

6 Visual disturbances after TURP are associated with:
A normal fundoscopic examination
B normal serum glycine concentrations
C normal intraocular pressure
D permanent alterations in vision

7 Recommendations for prevention of the TURP syndrome include:
A spinal anaesthetic
B hydrostatic pressure of irrigation fluid to be $6.9 \mathrm{kPa}\left(70 \mathrm{~cm} \mathrm{H}_{2} \mathrm{O}\right)$ or less
C open prostatectomy
D hypotonic intravenous fluid

8 Treatment of severe metabolic encephalopathy after TURP should be directed at:
A decreasing plasma glycine concentrations
B increasing extracellular fluid tonicity
C decreasing plasma ammonia concentrations
D ruling out potentially treatable conditions

9 Which of the following solutes contributes to plasma osmolality but not to tonicity:
A urea
B mannitol
C glycine
D sorbitol 